$\mathbb{P}$ periodica polytechnica

\author{
Chemical Engineering \\ $57 / 1-2(2013) 3$ \\ doi: 10.3311/PPch.2163 \\ http://periodicapolytechnica.org/ch \\ Creative Commons Attribution (1) \\ RESEARCH ARTICLE
}

\section{Modelling of Heat Transfer Processes with Compartment/Population Balance Model}

\author{
Zoltán Süle / Béla G. Lakatos / Csaba Mihálykó / Éva Orbán-Mihálykó
}

Received 2012-05-15, accepted 2013-01-09

\begin{abstract}
A compartment/population balance model is presented for describing heat transfer in gas-solid fluidized bed heat exchangers, modelling the particle-particle and particle-surface heat transfers by collisions. The results of numerical experimentation, obtained by means of a second order moment equation model indicate that the model can be used efficiently for analysing fluidized bed heat exchangers recovering heat either by direct particlefluid heat exchange or indirect tube-in-bed operation mode. The population balance model is validated with physically measured data taken from the literature [6].
\end{abstract}

\section{Keywords}

heat transfer · fluidized bed heat exchanger - compartment model $\cdot$ population balance model $\cdot$ simulation

\section{Acknowledgement}

This work was supported by the Hungarian Scientific Research Fund under Grant K77955 which is gratefully acknowledged. The financial support of the TAMOP-4.2.1/B-09/1/KONV2010-0003 project is also acknowledged.

This work was presented at the Conference of Chemical Engineering, Veszprém, 2012.

\section{Zoltán Süle}

Department of Computer Science and Systems Technology, University of Pannonia, Veszprém, Egyetem u. 10, Veszprém, H-8200, Hungary

Béla G. Lakatos

Department of Process Engineering, University of Pannonia, Veszprém, Egyetem u. 10, Veszprém, H-8200, Hungary

e-mail: lakatos@fmt.uni-pannon.hu

\section{Csaba Mihálykó}

\section{Éva Orbán-Mihálykó}

Department of Mathematics, University of Pannonia, Veszprém, Egyetem u. 10, Veszprém, H-8200, Hungary

\section{Introduction}

Fluidized bed heat exchangers, widely used in the metallurgical and process industries are important tools for recovering heat from hot solid particles [1]-[7]. In these systems heat exchange with the wall usually is modelled by means of suspension-wall heat transfer coefficients which, in principle, are aggregates of two transfer components: gas-wall and particle-wall heat transfers. However, because of intensive motion of particles, the particle-wall, and also the particle-particle heat transfers are collision induced processes thus it seems to be significant to model these processes by themselves. Using such modelling approach the gas-wall and particle-wall components can be separated that allows understanding the transfer mechanisms involved.

For modelling and simulation of collision heat transfer processes in gas-solid systems, an Eulerian-Lagrangian approach, with Lagrangian tracking for the particle phase $[8]-[11]$, and a population balance approach [12]-[16] have been applied. The population balance model, involving both the collision particleparticle and particle-wall heat transfers, was extended by Süle et al. [17, 18] for describing the spatial distributions of temperatures in deep or long fluidized beds developing a compartment model.

The aim of the paper is to extend the compartment population balance model to describe the heat transfer processes in fluidized bed heat exchangers in which the heat of hot solid particles is used to heat water flowing in tubes immersed in the bed. We apply a two-phase model of gas-solid fluidisation assuming that no bubbles are formed in the bed. The particle-particle and particletube heat transfers are modelled by collisions, while the gasparticle, gas-tube and tube-water heat transfers are described as continuous processes using linear driving forces.

\section{Physical model}

Consider a shallow fluidized bed in which particles transported horizontally through the bed are fluidized by cross-flow air fed into the system in equally distributed gas streams along the bed. Cold water to be heated is flowing inside a tube immersed in the bed. The fluidizing air induces intensive particleparticle and particle-tube collisions, and heat transfer between the gas, particles and water through the wall of the tube. 
The assumptions concerning the system are as follows: 1) The particles are of constant size and are not changed during the process; 2 ) The system is operated under steady state hydrodynamic conditions, and the influence of thermal changes on the hydrodynamics is negligible; 3) There is no heat source inside the particles. 4) The heat transfer by radiation is negligible.

The structure of the compartments, as well as of the mass and heat flows of the system is shown in Figure 1 In this system the following mass transport processes are distinguished.

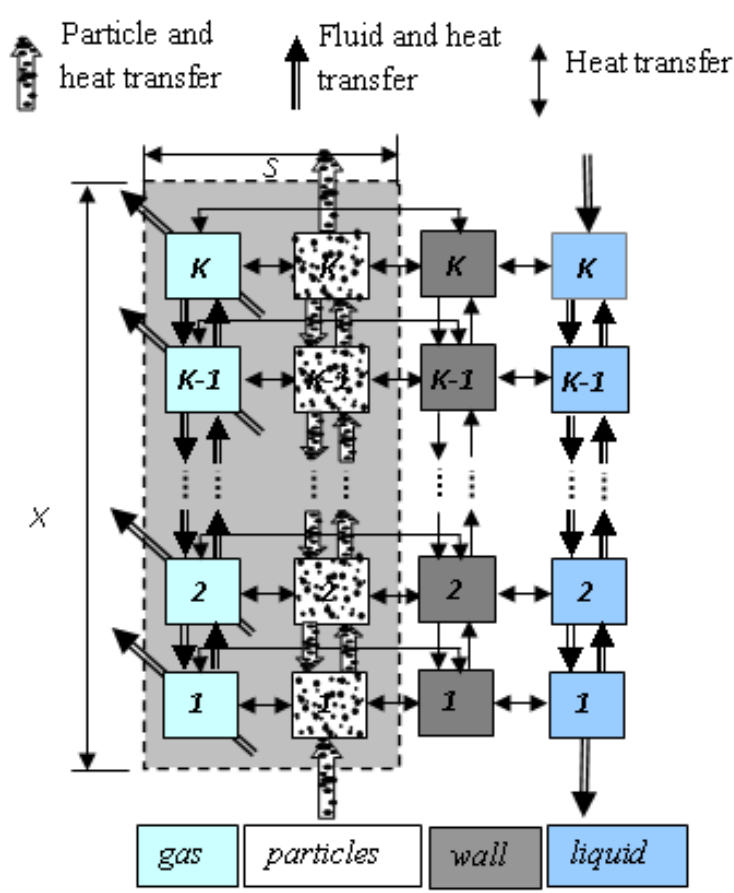

Fig. 1. The scheme of the system

(1) Volumetric cross-flow $q_{g}$ of the fluidizing gas through the ideally mixed cells between which some cross-mixing occurs. The temperature of gas in the $k^{\text {th }}$ cell is denoted by $T_{g, k}$, and there occurs continuous heat transfer between the gas and particles, and the gas and wall, characterised by the heat transfer coefficients $h_{g p}$, and $h_{g w}$, respectively.

(2) Dispersed plug flow of particles through the bed modelled by the cells-in-series with back-flow model. Here, $n_{k}\left(T_{p}, t\right)$ denote the population density function for the $k^{\text {th }}$ cell by means of which $n_{k}\left(T_{p}, t\right) \mathrm{d} T_{p}$ provides the number of particles from the interval $\left(T_{p}, T_{p}+d T_{p}\right)$ in a unit volume of the cell at time $t$. Inter-particle heat transfer occurs by collisions, and is described by the random variable $\Omega_{p p}$ with probability density function $f_{p p}$, while the particle-wall heat transfer also occurs by collisions that are characterised by the random variable $\Omega_{p w}$ with probability density function $f_{p w}$.

(3) The heat in the wall of the tube is transported by conduction, and the continuous wall-liquid heat transfer is characterised by the heat transfer coefficient $h_{w l}$.

(4) The volumetric flow $q_{l}$ of water inside the tube is modelled also by the cells-in-series with back-flow model. It is assumed to be counter-current one with respect to the volumetric flow of particles.
In the present model, as it is illustrated in Figure 1, all compartments (cells) describing the shallow fluidized bed are of the same volume $V_{k}$, while, for the sake of computational simplicity, the number of discrete elements of the tube wall and of the cells of model of flowing liquid, although their volumes are quiet different, are the same as that of the bed compartments along the axial direction $x$.

\section{Mathematical model}

Under these conditions, the mathematical model of the heat transfer processes of the system is formed by a mixed set of partial integral-differential, partial differential and ordinary differential equations. The population balance equation, which governs the variation of the population density function of particle population in the individual cells, is a partial integral differential equation and can be written as

$$
\begin{aligned}
& \frac{\partial n_{k}\left(T_{p}, t\right)}{\partial t}+\frac{a_{g p} h_{g p}}{c_{p} m_{p}} \frac{\partial\left[\left(T_{g ; k}(t)-T_{p}\right) n_{k}\left(T_{p}, t\right)\right]}{\partial T_{p}} \\
& =\frac{\left(1+S_{k} R_{p}\right) q_{p}}{V_{k}} n_{k-1}\left(T_{p}, t\right)+\frac{S_{k+1} R_{p} q_{p}}{V_{k}} n_{k+1}\left(T_{p}, t\right) \\
& -\frac{\left(1+Z_{k} R_{p}\right) q_{p}}{V_{k}} n_{k}\left(T_{p}, t\right)-S_{p w} n_{k}\left(T_{p}, t\right)-S_{p p} n_{k}\left(T_{p}, t\right) \\
& +S_{p w} \int_{0}^{1} n_{k}\left(\frac{T_{p}-p_{w} \omega_{p w} T_{w ; k}}{1-p_{w} \omega_{p w}}, t\right) \frac{f_{p w}\left(\omega_{p w}\right)}{1-p_{w} \omega_{p w}} \mathrm{~d} \omega_{p w} \\
& +\frac{2 S_{p p}}{M_{0 ; k}} \int_{T_{p \min }}^{T_{p \max }} \int_{0}^{1} \frac{f_{p p}\left(\omega_{p p}\right)}{\omega_{p p}} n_{k}\left(\frac{2\left(T_{p}-\tau\right)}{\omega_{p p}}+\tau, t\right) n_{k}(\tau, t) \mathrm{d} \omega_{p p} \mathrm{~d} \tau
\end{aligned}
$$

where $k=1,2, \ldots, K, t>0$, the variables

$$
\begin{aligned}
& \omega_{p p}:=1-\exp \left[\frac{-2 h_{p p} a_{p p} \theta_{p p}}{m_{p} c_{p}}\right] \text { and } \\
& \omega_{p w}:=1-\exp \left[\frac{-h_{p w} a_{p w} \theta_{p w}\left(m_{p} c_{p}+m_{w} c_{w}\right)}{m_{p} c_{p} m_{w} c_{w}}\right]
\end{aligned}
$$

represent the realizations of the random variables $\Omega_{p p}$ and $\Omega_{p w}$ which express, in principle, the efficiencies of the collision particle-particle and particle-tube wall heat transfers [16]. Here, $a_{g p}, a_{p p}$ and $a_{p w}$ denote, respectively, the gas-particle, particleparticle and particle-wall contact area, $\theta_{p p}$ and $\theta_{p w}$ denote the corresponding contact times and $R_{p}$ stands for the back-flow ratio of particles. Parameter $p_{w}$ represents the ratio of thermal capacities of particles and the wall, while parameters $S_{l}$ and $Z_{l}$ were introduced for characterising the compartmental structure of the system in a compact form where: $S_{1}=0, S_{K}=1, Z_{1}=$ $Z_{K}=1, S_{l}=1, Z_{l}=2, l=2, \ldots, K-1$.

The first term on the left hand side of Eq.(1) denotes the rate of accumulation of particles having temperature $\left(T_{p}, T_{p}+\mathrm{d} T_{p}\right)$, while the second term describes the change of the number of particles with temperature $\left(T_{p}, T_{p}+d T_{p}\right)$ due to the gas-particle heat transfer. The first three terms on the right hand side represent the input and output rates of particles from and to the 
neighbouring cells, as well as to and from the system, the next two terms describe the variation of the population density function due to the collision particle-tube wall heat transfer, while the last two terms describe the change of $n_{k}\left(T_{p}, t\right)$ because of the collision heat exchange between the particles.

The heat balance equations for the temperature of fluidizing gas in the individual cells become

$$
\begin{aligned}
\frac{d T_{g, 1}(t)}{d t} & =\frac{q_{g, 1}}{\varepsilon_{1} V_{1}} T_{g, 1, i n}(t)-\frac{q_{g, 1}}{\varepsilon_{1} V_{1}} T_{g, 1}(t)+\frac{\varepsilon_{2} R_{g} q}{\varepsilon_{1} V_{1}} T_{g, 2}(t) \\
& -\frac{\varepsilon_{1}\left(1+R_{g}\right) q}{\varepsilon_{1} V_{1}} T_{g, 1}(t) \frac{a_{g w} h_{g w}}{c_{g} \rho_{g}} \int_{0}^{x_{1}}\left(T_{g, 1}(t)-T_{w}(x, t)\right) \mathrm{d} x \\
& -\frac{a_{g p} h_{g p}}{c_{g} \rho_{g}} \int_{T_{p \min }}^{T_{p \max }}\left(T_{g, 1}(t)-T_{p}\right) n_{1}\left(T_{p}, t\right) \mathrm{d} T_{p}, \quad t>0
\end{aligned}
$$$$
\frac{d T_{g, k}(t)}{d t}=\frac{q_{g, k}}{\varepsilon_{k} V_{k}} T_{g, k, i n}(t)-\frac{q_{g, k}}{\varepsilon_{k} V_{k}} T_{g, k}(t)
$$$$
+\frac{\varepsilon_{k-1}\left(1+R_{g}\right) q}{\varepsilon_{k} V_{k}} T_{g, k-1}(t)
$$$$
+\frac{\varepsilon_{k+1} R_{g} q}{\varepsilon_{k} V_{k}} T_{g, k+1}(t)-\frac{\varepsilon_{k}\left(1+2 R_{g}\right) q}{\varepsilon_{k} V_{k}} T_{g, k}(t)
$$$$
-\frac{a_{g w} h_{g w}}{c_{g} \rho_{g}} \int_{x_{k-1}}^{x_{k}}\left(T_{g, k}(t)-T_{w}(x, t)\right) \mathrm{d} x
$$$$
-\frac{a_{g p} h_{g p}}{c_{g} \rho_{g}} \int_{T_{p \min }}^{T_{p \max }}\left(T_{g, k}(t)-T_{p}\right) n_{k}\left(T_{p}, t\right) \mathrm{d} T_{p}
$$$$
k=2, \ldots, K-1, t>0
$$

$$
\begin{aligned}
\frac{d T_{g, K}(t)}{d t} & =\frac{q_{g, K}}{\varepsilon_{K} V_{K}} T_{g, K, i n}(t)-\frac{q_{g, K}}{\varepsilon_{K} V_{K}} T_{g, K}(t) \\
& +\frac{\varepsilon_{K-1}\left(1+R_{g}\right) q}{\varepsilon_{K} V_{K}} T_{g, K-1}(t)-\frac{\varepsilon_{K}\left(1+R_{g}\right) q}{\varepsilon_{K} V_{K}} T_{g, K}(t) \\
& -\frac{a_{g w} h_{g w}}{c_{g} \rho_{g}} \int_{x_{K-1}}^{x_{K}}\left(T_{g, K}(t)-T_{w}(x, t)\right) \mathrm{d} x \\
& -\frac{a_{g p} h_{g p}}{c_{g} \rho_{g}} \int_{T_{p \min }}^{T_{p \max }}\left(T_{g, K}(t)-T_{p}\right) n_{K}\left(T_{p}, t\right) \mathrm{d} T_{p}, \quad t>0
\end{aligned}
$$

where $\varepsilon_{k}$ denotes the bed voidage in the $k^{\text {th }}$ cell, $q$ stands for the volumetric gas flow between the cells causing some crossmixing between the neighbour cells, $R_{g}$ denotes the back-flow ratio for gas, and coefficient $h_{g w}$ represents the gas-wall heat transfer rate. Since the gas is assumed to be fed into the system equally distributed along the axial coordinate $x$ we can write $\varepsilon_{k}=$ constant for all $k=1,2 \ldots K$.

Heat in the wall of tube is transported with conduction hence the differential equation describing the temperature of the wall can be written in the form

$$
\begin{aligned}
& \frac{\partial T_{w}(x, t)}{\partial t}=\frac{k_{w}}{\rho_{w} c_{w}} \frac{\partial^{2} T_{w}(x, t)}{\partial x^{2}}+\frac{a_{g w} h_{g w}}{c_{w} \rho_{w}}\left(T_{g, k}(t)-T_{w}(x, t)\right) \\
& +\frac{a_{w l} h_{w l}}{c_{w} \rho_{w}}\left(T_{w}(x, t)-T_{l, k}(t)\right) \\
& +S_{p w} \int_{T_{p \min }}^{T_{p \max }} \int_{0}^{1} p_{p} \omega_{p w}\left(T_{p}-T_{w}(x, t)\right) n_{k}\left(T_{p}, t\right) f_{p w}\left(\omega_{p w}\right) \mathrm{d} \omega_{p w} \mathrm{~d} T_{p}, \\
& t>0, x \in[(k-1) \Delta x, k \Delta x], k=1,2, \ldots, K,
\end{aligned}
$$

subject to the boundary conditions

$$
\left.\frac{\partial T_{w}(x, t)}{\partial x}\right|_{x=0}=0 \quad \text { and }\left.\quad \frac{\partial T_{w}(x, t)}{\partial x}\right|_{x=X}=0 .
$$

In Eq.66, $k_{w}$ denotes the thermal conductivity of the wall and the coefficient $h_{w l}$ stands for the wall-liquid heat transfer rate. Parameters $a_{g w}$ and $a_{w l}$ denote the surface area of gas-wall and wall-liquid heat transfers in a unit length of tube.

Finally, the set of differential equations for the temperature of liquid phase compartments is written as

$$
\begin{aligned}
& \frac{d T_{l, k}(t)}{d t}=\frac{S_{k-1} R_{l} q_{l}}{V_{l, k}} T_{l, k-1}(t) \\
& \quad+\frac{\left(1+S_{k+1} R_{l}\right) q_{l}}{V_{l, k}} T_{l, k+1}(t)-\frac{\left(1+Z_{k} R_{l}\right) q_{l}}{V_{l, k}} T_{l, k}(t) \\
& \quad+\frac{a_{w l} h_{w l}}{c_{l} \rho_{l}} \int_{x_{k-1}}^{x_{k}}\left(T_{w}(x, t)-T_{l, k}(t)\right) \mathrm{d} x, \quad k=1,2, \ldots, K, t>0
\end{aligned}
$$

where the values of the $S$ and $Z$ parameters, characterising the structure of the system are: $S_{0}=0, S_{K}=0, S_{K+1}=0, S_{l}=1$, $Z_{1}=Z_{K}=1, Z_{l}=2, l=1, \ldots, K-1$. The additional boundary conditions to Eqs (1)-(8) can be written as

$$
n_{0}\left(T_{p}, t\right)=n_{i n}\left(T_{p}, t\right) \quad \text { and } \quad T_{l, K+1}=T_{l, i n}
$$

which, naturally, should be completed with the appropriate initial conditions.

\section{Solution of the model equations}

The mixed set of differential equations (1)-9] was solved by reducing the population balance equation (1) and the heat conduction equation (6) into two sets of ordinary differential equations applying, respectively, a moment equation reduction and a finite difference discretization, obtaining in this way together with the gas phase equations (3)-(5) and liquid phase equation (8) a closed set of ordinary differential equations.

The moments and normalized moments of the temperature of particle population are defined as

$$
\begin{aligned}
& M_{I ; k}(t)=\int_{T_{p \min }}^{T_{p \max }} T_{p}^{I} n_{k}\left(T_{p}, t\right) d T_{p}, \\
& m_{I ; k}(t)=\frac{M_{I ; k}(t)}{M_{0 ; k}(t)}, \quad I=0,1,2, \ldots, k=1, \ldots, K
\end{aligned}
$$


which are useful for the basic characterisation of the temperature distribution of particles. The zero order moments $M_{0 ; k}$ provide the total numbers of particles in a unit volume of cells by means of which the solids concentrations can also be computed, while the mean temperature of particles in the $k^{\text {th }}$ cell is expressed by $m_{1 ; k}(t)$. Completing the zero and first order moments $M_{0 ; k}$ and $M_{1 ; k}$ with the second order one $M_{2 ; k}$, the variance of temperature, defined as

$$
\sigma_{k}^{2}=\frac{M_{2 ; k}}{M_{0 ; k}}-\left(\frac{M_{1 ; k}}{M_{0 ; k}}\right)^{2}
$$

can also be computed.

The infinite hierarchy of the moment equations generated by the population balance equation (1) has the form

$$
\begin{aligned}
& \frac{d M_{I ; k}(t)}{d t}=I K_{g p}\left[M_{I-1 ; k}(t) T_{f ; k}(t)-M_{I ; k}(t)\right] \\
& +S_{p p}\left[\frac{1}{M_{0 ; k}(t)} \sum_{i=0}^{I} M_{i ; k}(t) M_{I-i ; k}(t) b_{i, I}^{(p p)}-M_{I ; k}(t)\right] \\
& +S_{p w} p_{1}\left[-M_{I ; k}(t)+\sum_{i=0}^{I}\left(\begin{array}{l}
I \\
i
\end{array}\right) b_{i}^{(p w)} \sum_{j=0}^{i}\left(\begin{array}{l}
i \\
j
\end{array}\right)(-1)^{i-j} T_{w ; k}^{j} M_{I-j ; k}(t)\right] \\
& +\frac{\left(1+S_{k} R_{p}\right) q_{p}}{V} M_{I ; k-1}(t) \\
& +\frac{R_{p} q_{p}}{V} M_{I ; k+1}(t)-\frac{\left(1+Z_{k} R_{p}\right) q_{p}}{V} M_{I ; k}, \\
& \quad k=1,2, \ldots, K, I=0,1, \ldots, t>0
\end{aligned}
$$

where

$$
\begin{aligned}
& b_{i, I}^{(p p)}=\int_{0}^{1}\left(\begin{array}{l}
I \\
i
\end{array}\right)\left(\frac{\omega_{p p}}{2}\right)^{i}\left(1-\frac{\omega_{p p}}{2}\right)^{I-i} f_{p p}\left(\omega_{p p}\right) \mathrm{d} \omega_{p p} \quad \text { and } \\
& b_{i}^{(p w)}=\int_{0}^{1} \omega_{p w}^{i} f_{p w}\left(\omega_{p w}\right) \mathrm{d} \omega_{p w} .
\end{aligned}
$$

Since the infinite set of moment equations can be closed at any order, the second order moment equation reduction can be computed exactly by solving the equations for the first three leading moments. This reduction is obtained by using the following equations. The total number of particles in the $k^{\text {th }}$ cell:

$$
\begin{aligned}
\frac{d M_{0 ; k}(t)}{d t}= & \frac{\left(1+S_{k} R_{p}\right) q_{p}}{V} M_{0 ; i n}(t) \\
& +\frac{R_{p} q_{p}}{V} M_{0 ; k+1}(t)-\frac{\left(1+Z_{k} R_{p}\right) q_{p}}{V} M_{0 ; k}(t), \\
& k=1,2, \ldots, K
\end{aligned}
$$

The first order moment of the particulate phase in the $k^{\text {th }}$ cell:

$$
\begin{aligned}
\frac{d M_{1 ; k}(t)}{d t}= & \frac{a_{g p} h_{g p}}{c_{g} \rho_{g}}\left(M_{0 ; k}(t) T_{g ; k}(t)-M_{1 ; k}(t)\right) \\
& +S_{p w} p_{w} b_{1}^{(p w)}\left(M_{0 ; k}(t) T_{w ; k}(t)-M_{1 ; k}(t)\right) \\
& +\frac{\left(1+S_{k} R_{p}\right) q_{p}}{V} M_{1 ; i n}(t) \\
& +\frac{R_{p} q_{p}}{V} M_{1 ; k+1}(t)-\frac{\left(1+Z_{k} R_{p}\right) q_{p}}{V} M_{1 ; k}(t), \\
& k=1,2, \ldots, K
\end{aligned}
$$

The variance of temperature of the particulate phase in the $k^{\text {th }}$ cell:

$$
\begin{aligned}
\frac{d \sigma_{k}^{2}(t)}{d t} & =-\left[2 \frac{a_{g p} h_{g p}}{c_{g} \rho_{g}}+S_{p p} b_{1,2}^{(p p)}+S_{p w} p_{w}\left(2 b_{1}^{(p w)}-p_{w} b_{2}^{(p w)}\right)\right. \\
& \left.+\frac{q_{p}}{V M_{0 ; k}(t)}\left(R_{p} M_{0 ; k+1}(t)\right)\right] \cdot \sigma_{k}^{2}(t) \\
& +\frac{q_{p}}{V} \frac{\left(1+S_{k} R_{p}\right) M_{0, i n}(t)}{M_{0 ; k}(t)}\left(\sigma_{i n}^{2}(t)-\sigma_{k}^{2}(t)\right) \\
& +S_{p w} b_{2}^{(p w)} p_{w}^{2}\left(\frac{M_{1 ; k}(t)}{M_{0 ; k}(t)}-T_{w ; k}(t)\right)^{2} \\
& +\frac{q_{p}\left(1+S_{k} R_{p}\right) M_{0 ; i n}(t)}{V M_{0 ; k}(t)}\left(\frac{M_{1 ; i n}(t)}{M_{0 ; i n}(t)}-\frac{M_{1 ; k}(t)}{M_{0 ; k}(t)}\right)^{2} \\
& +\frac{R_{p} q_{p} M_{0 ; k+1}(t)}{V M_{0 ; k}(t)} \sigma_{k+1}^{2}(t) \\
& +\frac{R_{p} q_{p} M_{0 ; k+1}(t)}{V M_{0 ; k}(t)}\left(\frac{M_{1 ; k+1}(t)}{M_{0 ; k+1}(t)}-\frac{M_{1 ; k}(t)}{M_{0 ; k}(t)}\right)^{2}, k=1,2, \ldots, K
\end{aligned}
$$

The set of equations provided with finite difference discretization of the heat conduction equation 6 for the wall has the form:

$$
\begin{aligned}
& \frac{d T_{w, 1}(t)}{d t}=\frac{D_{T}}{\Delta x^{2}}\left(T_{w, 2}(t)-T_{w, 1}(t)\right) \\
& +\frac{a_{g w} h_{g w}}{c_{w} \rho_{w}}\left(T_{g, 1}(t)-T_{w, 1}(t)\right)-\frac{a_{w l} h_{w l}}{c_{w} \rho_{w}}\left(T_{w, 1}(t)-T_{l, 1}(t)\right) \\
& -S_{p w} \int_{T_{p \min }}^{T_{p \max }} \int_{0}^{1} p_{p}\left(T_{w, 1}(t)-T_{p}\right) n_{1}\left(T_{p}, t\right) \omega_{p w} f_{p w}\left(\omega_{p w}\right) d \omega_{p w} d T_{p}, \\
& t>0 \\
& \frac{d T_{w, k}(t)}{d t}=\frac{D_{T}}{\Delta x^{2}}\left(T_{w, k+1}(t)-2 T_{w, k}(t)+T_{w, k-1}(t)\right) \\
& +\frac{a_{g w} h_{g w}}{c_{w} \rho_{w}}\left(T_{g, k}(t)-T_{w, k}(t)\right)-\frac{a_{w l} h_{w l}}{c_{w} \rho_{w}}\left(T_{w, k}(t)-T_{l, k}(t)\right) \\
& -S_{p w} \int_{T_{p \min }}^{T_{p \max }} \int_{0}^{1} p_{p}\left(T_{w, k}(t)-T_{p}\right) n_{k}\left(T_{p}, t\right) \omega_{p w} f_{p w}\left(\omega_{p w}\right) d \omega_{p w} d T_{p} \\
& k=2,3, \ldots, K-1, \quad t>0 \\
& \frac{d T_{w, K}(t)}{d t}=\frac{D_{T}}{\Delta x^{2}}\left(T_{w, K}(t)-T_{w, K-1}(t)\right) \\
& +\frac{a_{g w} h_{g w}}{c_{w} \rho_{w}}\left(T_{g, K}(t)-T_{w, K}(t)\right)-\frac{a_{w l} h_{w l}}{c_{w} \rho_{w}}\left(T_{w, K}(t)-T_{l, K}(t)\right) \\
& -S_{p w} \int_{T_{p \min }}^{T_{p \max }} \int_{0}^{1} p_{p}\left(T_{w, K}(t)-T_{p}\right) n_{K}\left(T_{p}, t\right) \omega_{p w} f_{p w}\left(\omega_{p w}\right) d \omega_{p w} d T_{p}, \\
& t>0
\end{aligned}
$$

so that the integrals of variable $x$ in Eqs (3)-(5) for the fluidizing gas and Eqs $(8)$ for the liquid flowing in the tube are also rewritten for the discrete values $T_{w, k}(t), k=1,2, \ldots, K$. 


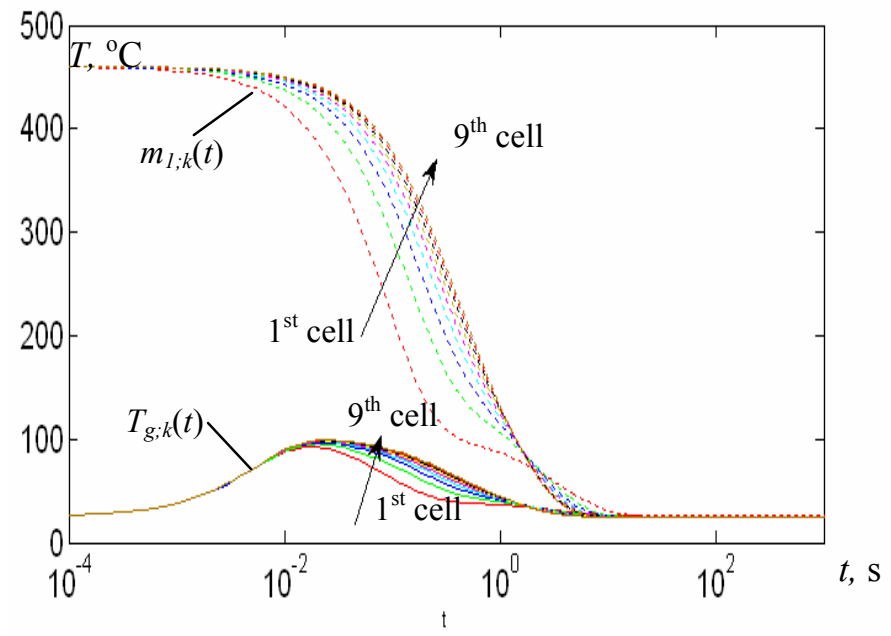

Fig. 2. Transients of the mean temperature of particles and the temperature of air in the cells

\section{Simulation results and discussion of the models}

A computer program was developed in MATLAB environment for solving the set of ordinary differential equations (3) (5), (8) and (14)-(19) taking into account all modifications of the integral terms. The program can generate and handle a compartment/moment equations model consisted of cells of arbitrary number, and the resulted set of ordinary differential equations is solved by means of an ode-solver of MATLAB. The transient and steady state simulation results presented here were obtained for 9 cells using the basic constitutive expressions presented in detail in [16].

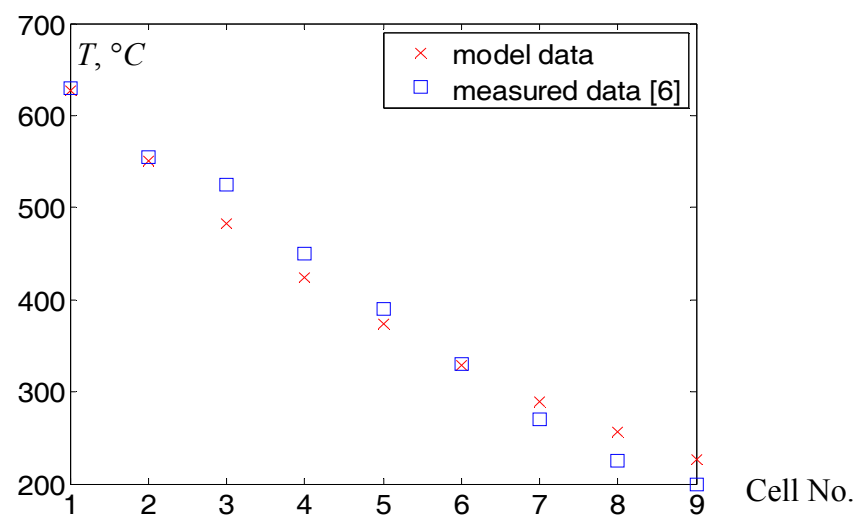

Fig. 3. The results of the compartment/population balance model compared with the experimental data by Pécora and Parise [6] when the input temperatures of particles were $708^{\circ} \mathrm{C}$

The predictions of the second order moment equation reduction model were validated using the experimental data measured in a laboratory shallow fluidized bed heat exchanger published by Pécora and Parise [6]. Figure 3 presents the bed temperature profiles for 9 cells comparing the model data with the measured ones [6] when the input temperatures of particles were $708{ }^{\circ} \mathrm{C}$, respectively. The parameters were fitted to the measured values using a least squares method. The results in both

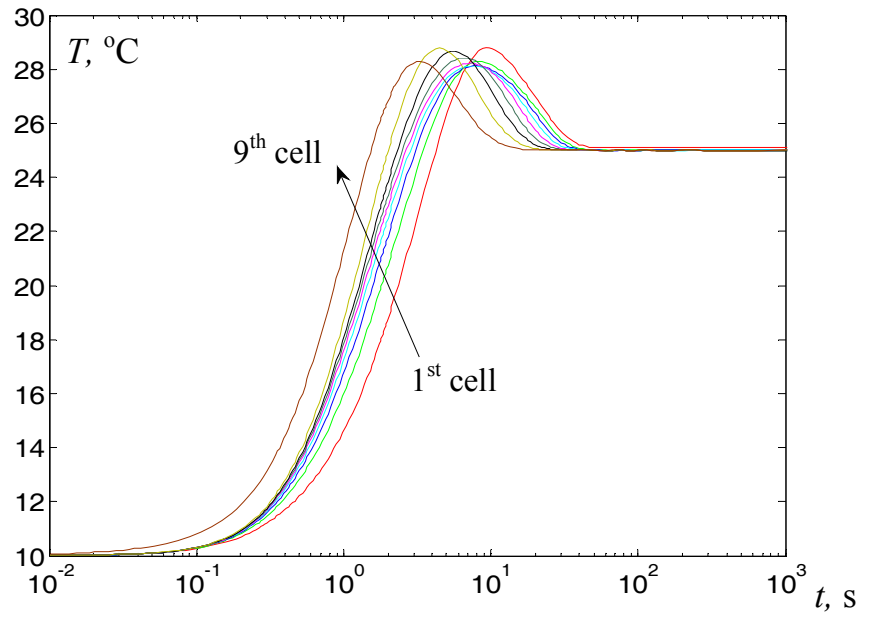

Fig. 4. Transients of the temperature of water flowing in the tube

cases show rather good correspondence but it has to be taken only as preliminary ones since the heat transfer coefficients have been compared yet. Figure 2 presents the transients of the mean temperature of particles and the temperature of the fluidizing air in the cells along the heat exchanger. It is seen that in steady state these temperatures become almost equal and the heat of hot particles becomes transferred to the cold water. Under such conditions, the temperature of gas passes a maximum in each cell but delayed to each other in time. Similar maxima can be observed also in the transient processes of the wall, and in the temperature of liquid, as it is presented in Figure 4 , heated by the hot particles through the tube wall.

Figure 5 shows the variation of the variance of temperature of particle population as a function of time. The temperature of particles at the input was homogeneous but it became strongly distributed during the transient process showing rather large variances. The simulation results have shown that the gasparticle and particle-wall heat transfers induce inhomogeneities of the temperature of particles but the particle-particle collision heat transfer shows a strong indirect effect.

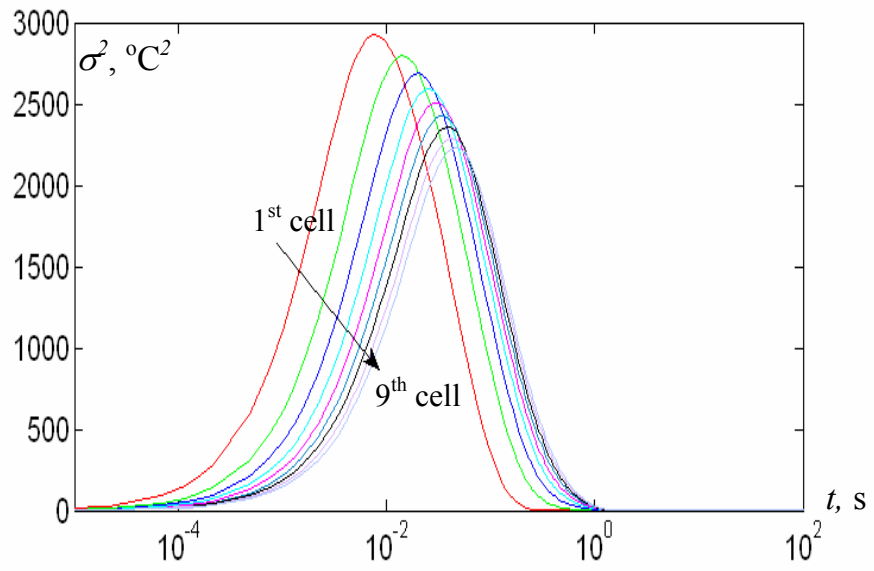

Fig. 5. Transients of the variance of temperature of particle population 
Tab. 1. The basic constitutive and process parameters used in simulation

\begin{tabular}{|c|c|c|}
\hline & Parameter & Basic value \\
\hline \multirow[t]{6}{*}{ Solid particles: sand } & Diameter, $d_{p}$ & $2.54 \times 10^{-4} \mathrm{~m}$ \\
\hline & Density, $\rho_{p}$ & $2650 \mathrm{~kg} \mathrm{~m}^{-3}$ \\
\hline & Specific heat, $c_{p}$ & $835 \mathrm{~J} \mathrm{~kg}^{-1} \mathrm{~K}^{-1}$ \\
\hline & Thermal conductivity, $k_{p}$ & $0.35 \mathrm{~W} \mathrm{~m}^{-1} \mathrm{~K}^{-1}$ \\
\hline & Volumetric flow rate, $q_{p}$ & $1.5 \times 10^{-5} \mathrm{~m}^{3} \mathrm{~s}^{-1}$ \\
\hline & Mean inlet temperature, $m$ & $460^{\circ} \mathrm{C}$ \\
\hline \multirow[t]{6}{*}{ Gas: air } & Density, $\rho_{g}$ & $0.946 \mathrm{~kg} \mathrm{~m}^{-3}$ \\
\hline & Specific heat, $c_{g}$ & $1010 \mathrm{~J} \mathrm{~kg}^{-1} \mathrm{~K}^{-1}$ \\
\hline & Viscosity, $\mu_{g}$ & $2.17 \times 10^{-5} \mathrm{~Pa} \mathrm{~s}$ \\
\hline & Thermal conductivity, $k_{g}$ & $2.39 \times 10^{-2} \mathrm{~W} \mathrm{~m}^{-1} \mathrm{~K}^{-1}$ \\
\hline & Volumetric flow rate, $q_{g}$ & $1.4 \times 10^{-2} \mathrm{~m}^{3} \mathrm{~s}^{-1}$ \\
\hline & Inlet temperature & $25^{\circ} \mathrm{C}$ \\
\hline \multirow[t]{4}{*}{ Tube wall: stainless steel } & Diameter, $D_{l}$ & $0.0065 \mathrm{~m}$ \\
\hline & Mass, $m_{w}$ & $1.2 \mathrm{~kg}$ \\
\hline & Specific heat, $c_{w}$ & $465 \mathrm{~J} \mathrm{~kg}^{-1} \mathrm{~K}^{-1}$ \\
\hline & Thermal conductivity, $k_{w}$ & $44 \mathrm{~W} \mathrm{~m}^{-1} \mathrm{~K}^{-1}$ \\
\hline \multirow[t]{6}{*}{ Heated medium: water } & Density, $\rho_{l}$ & $998 \mathrm{~kg} \mathrm{~m}^{-3}$ \\
\hline & Specific heat, $c_{l}$ & $4182 \mathrm{~J} \mathrm{~kg}^{-1} \mathrm{~K}^{-1}$ \\
\hline & Thermal conductivity, $k_{l}$ & $0.606 \mathrm{~W} \mathrm{~m}^{-1} \mathrm{~K}^{-1}$ \\
\hline & Viscosity, $\mu_{l}$ & $10^{-3} \mathrm{~Pa} \mathrm{~s}$ \\
\hline & Volumetric flow rate, $q_{l}$ & $1.5 \times 10^{-5} \mathrm{~m}^{3} \mathrm{~s}^{-1}$ \\
\hline & Inlet temperature & $25^{\circ} \mathrm{C}$ \\
\hline \multirow[t]{4}{*}{ Fluidized bed } & Width, $W$ & $0.15 \mathrm{~m}$ \\
\hline & Length, $L$ & $0.9 \mathrm{~m}$ \\
\hline & Collision frequencies, $S_{p p}, S_{p w}$ & $10^{3} \mathrm{~s}^{-1}, 10 \mathrm{~s}^{-1}$ \\
\hline & Heat transfer efficiencies $\mu_{p p}, \mu_{p w}$ & $0.5,0.8$ \\
\hline Back flow ratio & $R_{p}, R_{g}, R_{l}$ & $1,0.1,0.01$ \\
\hline \multirow[t]{4}{*}{ Heat transfer coefficients } & $h_{p g}$ & $1.46 \times 10^{2}$ \\
\hline & $h_{w p}$ & $5.58 \times 10^{2}$ \\
\hline & $h_{w l}$ & $4.35 \times 10^{9}$ \\
\hline & $h_{g w}$ & $6.06 \times 10^{-2}$ \\
\hline
\end{tabular}

\section{Conclusions}

The compartment/population balance model, developed for describing heat transfer processes in gas-solid fluidized bed heat exchangers, and modelling the particle-particle and particlesurface heat transfer processes by collisions can be used efficiently for analysing the fluidized bed heat exchangers recovering heat from hot particles and heating some liquid flowing in a tube immersed in the bed. The model describes the temperature distribution of the particle population, and allows separating the effects of the fluidizing gas-immersed surface and particle-immersed surface heat transfers. The second order moment equation reduction, generated from the population balance equation has proved to be an efficient tool for studying the behaviour of heat exchangers.

\section{References}

1 Elliot DE, Holme BG, Fluidized bed heat exchangers, IChemE; London, UK, 1976.

2 Rautenbach R, Katz T, Survey of long time behaviour and costs of industrial fluidized bed heat exchangers, Desalination, 108, (1997), 335.

3 Rodriguez OMH, Pecora AAB, Bizzo WA, Heat recovery from hot solid particles in a shallow fluidized bed, Applied Thermal Engineering, 22, (2002), 145.
4 Aghajani M, Müller-Steinhagen $\mathbf{H}$, Jamialahmadi $\mathbf{M}$, New design equations for liquid/solid fluidized bed heat exchangers, Int. J. Heat Mass Transfer, 48, (2005), 317.

5 Ahn SW, Bae ST, Lee BC, Kim WC, Bae MW, Fluid flow and heat transfer in fluidized bed vertical shell and tube heat exchanger, Int. Comm. Heat Mass Transfer, 32, (2005), 224.

6 Pécora AAB, Parise MR, Heat transfer coefficient in a shallow fluidized bed heat exchanger with a continuous flow of solid particles, Journal of the Brazilian Society of Mechanical Sciences and Engineering, 28, (2006).

7 Rajan KS, Srivastava SN, Pitchumani B, Mahonty B, Simulation of countercurrent gas-solid heat exchanger: Effect of solid loading ratio and particle size, Appl. Therm. Eng., 27, (2007), 1345.

8 Boulet P, Moissette S, Andreaux R, Osterlé B, Test of an EulerianLagrangian simulation of wall heat transfer in a gas-solid pipe flow, Int. J. Heat Fluid Flow., 21, (2000), 381.

9 Mansoori Z, Saffar-Avval M, Basirat-Tabrizi H, Ahmadi G., Lain S, Thermo-mechanical modeling of turbulent heat transfer in gas-solid flows including particle collisions, Int. J. Heat Fluid Flow Transfer., 23, (2002), 792.

10 Chagras V., Osterlé B., Boulet P, On heat transfer in gas-solid pipe flows: Effects of collision induced alterations on the flow dynamics, Int. J. Heat Mass Transfer., 48, (2005), 1649.

11 Mansoori Z, Saffar-Avval M, Basirat-Tabrizi H, Dabir B, Ahmadi G, Interparticle heat transfer in a riser of gas-solid turbulent flows, Powder Tech., 159, (2005), 35. 
12 Mihálykó C, Lakatos BG, Blickle T, Modelling heat transfer between solid particles, Math. Comp. Simul., 53, (2000), 403.

13 Mihálykó C, Lakatos BG, Matejdesz A, Blickle T, Population balance model for particle-to-particle heat transfer in gas-solid systems, Int. J. Heat Mass Transfer, 47, (2004), 1325.

14 Lakatos BG, Mihálykó C, Blickle T, Modelling of interactive populations of disperse systems, In: Proc. $2^{\text {nd }}$ Int. Conf. Population Balance Modelling, Valencia, 2005, p. 72.

15 Lakatos BG, Mihálykó C, Blickle T, Modelling of interactive populations of disperse system, Chem. Eng. Sci., 61, (2006), 54.

16 Lakatos BG, Süle Z, Mihálykó C, Modelling of interactive populations of disperse system, Int. J. Heat Mass Transfer, 51, (2008), 1633.

17 Süle Z, Mihálykó C, Lakatos BG, Population balance model of gassolid fluidized bed heat exchangers, Chemical and Process Engineering, 29, (2008), 201.

18 Süle Z, Mihálykó C, Lakatos BG, Modelling of heat transfer processes in particulate systems, In: Marquardt W, Pantelides C (eds.), Proc. $16^{\text {th }}$ ESCAPE and $9^{\text {th }}$ ISPSE. Comp-Aided Chem. Eng., Vol. 21 A, Elsevier; Amsterdam, 2006, p. 589.

\section{Subscripts and superscripts}

$g \quad$ gas

in input

$l \quad$ liquid

$\max$ maximal value

$\min$ minimal value

$p$ particle

$g p$ gas-particle

pp particle-particle

$p w$ particle-wall

$w \quad$ wall

gw gas-wall

$w l \quad$ wall-liquid

\section{Symbols}

a surface area, $\mathrm{m}^{2}$

c specific heat, $\mathrm{J} \mathrm{kg}^{-1} \mathrm{~K}^{-1}$

$d \quad$ diameter $(m)$

$W \quad$ width of the bed, $m$

$D$ diameter of the tube, $\mathrm{m}$

$D_{T} \quad$ thermal diffusivity, $D_{T}=k_{w} / \rho_{w} c_{w}, \mathrm{~m}^{2} \mathrm{~s}^{-1}$

$f \quad$ probability density function

$h$ heat transfer coefficient, $\mathrm{W} \mathrm{m}^{-2} \mathrm{~K}^{-1}$

$k$ thermal conductivity, $\mathrm{W} \mathrm{m}^{-1} \mathrm{~K}^{-1}$

$K \quad$ number of cells

$L \quad$ length of fluidized bed $(m) \quad m$ - mass, $\mathrm{kg}$

$M_{k} \quad k^{\text {th }}$ order moment of particle temperature

$m_{k} \quad$ normalised $k^{t h}$ order moment of particle temperature

$n \quad$ population density function, no $\mathrm{m}^{-3} \mathrm{~K}^{-1}$

$p_{p} \quad$ parameter in Eq. $\left\{1, p_{p}=\frac{m_{w} c_{w}}{m_{p} c_{p}+m_{w} c_{w}}\right.$

$p_{w} \quad$ parameter in Eq. $11, p_{w}=\frac{m_{p} c_{p}}{m_{p} c_{p}+m_{w} c_{w}}$

$q \quad$ volumetric flow rate, $\mathrm{m}^{3} \mathrm{~s}^{-1}$

$R \quad$ back-flow ratio

$S \quad$ collision frequencie, $\mathrm{s}^{-1}$

$T$ temperature, $\mathrm{K}$

$t$ time, $\mathrm{s}$

$V \quad$ volume, $\mathrm{m}^{3}$

$x \quad$ axial variable, $\mathrm{m}$

$X \quad$ length of the fluidized bed, $\mathrm{m}$

$\theta \quad$ contact time, $\mathrm{s}$

$\omega$ random variable of collision heat transfer

$\mu \quad$ viscosity, $\mathrm{Pa} \mathrm{s}$

$\varepsilon \quad$ void fraction of the bed

$\sigma^{2} \quad$ variance of the temperature of particle population

$\rho$ density, $\mathrm{kg} \mathrm{m}^{-3}$

$\tau \quad$ integral variable, $\mathrm{K}$ 